Article

\title{
Enantioselective Extraction of Phenylalanine Enantiomers Using Environmentally Friendly Aqueous Two-Phase Systems
}

\author{
Danyu Sun ${ }^{1,+}$, Runping Wang ${ }^{3,+}$, Fenfang Li ${ }^{1, *}$, Lianglei Liu ${ }^{1}$ and Zhijian Tan ${ }^{1,2, *(D)}$ \\ 1 College of Chemistry and Chemical Engineering, Central South University, Changsha 410083, China; \\ danyusun@163.com (D.S.); liulianglei@csu.edu.cn (L.L.) \\ 2 Institute of Bast Fiber Crops and Center of Southern Economic Crops, \\ Chinese Academy of Agricultural Sciences, Changsha 410205, China \\ 3 School of Chemistry and Chemical Engineering, Qiannan Normal University for Nationalities, \\ Duyun 558000, China; runpingw0826@163.com \\ * Correspondence: lfflqq@csu.edu.cn (F.L.); tanzhijian@caas.cn (Z.T.); Tel.: +86-731-8899-8517 (F.L. \& Z.T.) \\ + These authors contributed equally to this work.
}

Received: 9 October 2018; Accepted: 23 October 2018; Published: 1 November 2018

\begin{abstract}
Background: The environmentally friendly choline-amino acid ionic liquids (ChAAILs) and deep eutectic solvents (DESs) have been used as excellent alternatives to volatile organic compounds (VOCs) and ionic liquids (ILs) in recent years; (2) Methods: Thus, ChAAILs/salt and DESs/salt aqueous two-phase systems (ATPSs) were developed for the chiral extraction of phenylalanine enantiomers. The optimum ATPS of [Ch][L-Pro] $/ \mathrm{K}_{3} \mathrm{PO}_{4}$ was chosen, and the influencing parameters were investigated, including ChAAILs concentration, salt concentration, chiral selector concentration, extraction temperature, phenylalanine concentration, and system $\mathrm{pH}$; (3) Results: The phenylalanine enantiomers were mainly extracted into the top phase (ChAAIL-rich phase), meanwhile, the (S)-phenylalanine [(S)-Phe)] was preferentially recognized by the chiral selector in the top phase. The maximum separation factor $(\alpha)$ of 2.05 was obtained under the optimal conditions; and (4) Conclusions: This ATPS that was used for the chiral extraction of enantiomers is much more environmentally friendly, simple, and rapid, and has the potential to be used in the enantioselective extraction of other enantiomers.
\end{abstract}

Keywords: enantioselective extraction; aqueous two-phase system; ionic liquids; deep eutectic solvents; phenylalanine

\section{Introduction}

Nowadays, more and more attention has been paid to chirality in the pharmaceuticals, agrochemicals, and food industries. As we all know, the two enantiomers in some chiral drugs produce different actions, and one can be used as a therapeutic drug, while the other is useless or even toxic. Thus, it is of great importance to acquire the optically pure enantiomer. Up until now, the enantiomeric resolution is still the major method for obtaining the single enantiomer. Many methods are used for the enantioseparation of enantiomers, including chemical resolution [1], chromatographic (such as thin-layer chromatography [2], liquid chromatography [3], gas chromatography [4], and capillary electrophoresis [5], et al.), enzymatic or microbiological methods [6,7], membranous resolution [8], various extraction methods (such as liquid-liquid extraction [9], solid-liquid two-phase system [10], magnetic solid-phase extraction [11], and ligand exchange extraction [12]), and the metal-organic frameworks (MOFs) method [13]. Among these methods, the chiral liquid-liquid extraction is simple, 
low cost, and easy to scale up [14,15]. Simultaneously, the tartaric esters derivatives, metal complexes, cyclodextrin derivatives, crown ethers, and chiral ionic liquids are the most commonly used chiral selectors in the enantioselective liquid-liquid extraction.

The aqueous two-phase system (ATPS) is a kind of liquid-liquid extraction method, which was first reported by Albertsson [16]. The PEG/Dextran and PEG/salt are the most common ATPSs, then the surfactant [17], thermo-sensitive copolymer [18], pH-responsive copolymer [19], small molecule alcohol [20], ionic liquid (ILs) [21], and deep eutectic solvent (DESs) based ATPSs emerged [22]. ATPSs were used in the extraction field, like proteins, organic molecules, and metal ions [23]. In recent years, various ATPSs were also used in the enantioseparation of the enantiomers, such as the polymer/salt system [24-26], the polymer/polymer system [15], the alcohol/salt system [27,28], and the ILs/salt system $[29,30]$. These ATPSs have the disadvantages of use of polymers with high viscosity (e.g., PEG), volatile organic solvents (e.g., ethanol), or common ILs with relatively higher biotoxicity and poorer biodegradability (e.g., imidazolium ILs).

Recently, ILs were considered as the green solvents. However, more and more studies began to query the "green" feature of ILs, and a mass of literature has proved the biotoxicity and poor biodegradability of some commonly used ILs, such as those ILs with different cations (imidazolium, pyridinium, quaternary ammonium) and anions (halide, tetrafluoroborate, hexafluorophosphate) [31-33]. Compared with the commonly used ILs, the choline-amino acid ionic liquids (ChAAILs) and deep eutectic solvents (DESs) can be easily prepared from renewable biomaterials and have proved to be more environmentally friendly solvents [34-36] which can be readily biodegradable and used as alternatives to the conventional ILs. ChAAILs were prepared from renewable starting materials of choline chloride and various amino acids, and their preparation was much easier via a neutralization reaction without producing toxic byproduct compared with the conventional ILs [34]. Deep eutectic solvents (DESs) were referred to as ILs analogue, which consist of two or three hydrogen bond acceptors (HBAs) and hydrogen bond donors (HBDs) at room temperature [37,38]. Compared with ILs, DESs have some unique merits, for example, no or lower toxicity, higher biodegradability, easier preparation, and lower material cost [37,39,40].

In this study, the environmentally friendly ATPSs of ChAAILs/salt and DESs/salt were applied for the chiral separation of phenylalanine enantiomers. Hydroxypropyl-beta-cyclodextrin (HP- $\beta$-CD) had good water solubility and was chosen as the chiral selector that was added into the ATPS. The optimum [Ch][L-Pro] $/ \mathrm{K}_{3} \mathrm{PO}_{4}$ system was screened, and then the factors were studied, including the concentrations of ChAAIL, salt, and chiral selector, extraction temperature, loaded sample concentration, and system $\mathrm{pH}$. The enantioseparation of phenylalanine enantiomers using this ATPS could be completed by a single step extraction in a few seconds, and satisfactory results were obtained.

\section{Materials and Methods}

\subsection{Materials and Reagents}

Choline chloride ( $\mathrm{ChCl}, \mathrm{AR}>98 \%$ ), betaine ( $\mathrm{AR}>98 \%$ ), L-proline (L-Pro, purity > 99\%), L-cysteine (L-Cys, purity > 99\%), L-histidine (L-His, purity > 99\%), L-valine (L-Val, purity > 99\%), L-serine (L-Ser, purity > 99\%), L-methionine (L-Met, purity > 99\%), L-alanine (L-Ala, purity > 99\%), urea (purity $>99.5 \%$ ), D-sorbitol (D-Sor, AR $>98 \%$ ), L-lactic acid (L-LA, high purity grade $>90 \%$ ), D-glucose (D-Glu, AR > 98\%), and glycol (Gly, GC > 98\%) were provided by Aladdin Reagent Co., Ltd. (Shanghai, China). The racemic DL-phenylalanine (HPLC purity $>98 \%$ ), (S)-phenylalanine $[(S)$-Phe] and $(R)$-phenylalanine enantiomers $[(R)$-Phe] (chiral purity $>99 \%$ ) were purchased from Aladdin Reagent Co., Ltd. (Shanghai, China). The inorganic salt of potassium phosphate and monopotassium phosphate were analytical reagents (purity $>98 \%$ ) and were provided by Aladdin Reagent Co., Ltd. (Shanghai, China). O-phthalaldehyde (OPA) (purity > 98\%) and N-acetyl-L-cysteine (NAC) (purity $>99 \%$ ) were provided by Aladdin Reagent Co., Ltd. (Shanghai, China). HPLC grade acetonitrile was provided by TEDIA Company, Inc. (Fairfield, OH, USA). 


\subsection{Preparation of ChAAILs and DESs}

The ChAAILs were synthesized using the "two-step" method [41]. Briefly, the choline hydroxide was prepared by exchanging the $\mathrm{ChCl}$ by adding the sodium hydroxide solution in anion exchange resin. Then, the ChAAILs were prepared by neutralizing the choline hydroxide with the corresponding amino acids mentioned above, respectively. The ChAAILs were washed by methanol and acetonitrile (1:9) to remove the salt and unreacted amino acids. The ChAAILs were obtained by removing the solvents and were then dried in a vacuum drying oven. The ChAAILs were characterized by ${ }^{1} \mathrm{HNMR}$, and the data was in accord with the results in our previous work and other reports [42,43].

The DESs were obtained referring to the method reported in other literature [44]. The HBDs and HBAs were mixed in a round-bottom flask. The flask was placed on a magnetic stirring apparatus at $80^{\circ} \mathrm{C}$ by constant stirring for $3-4 \mathrm{~h}$ until a homogeneous liquid was obtained.

\subsection{Phase Diagrams}

The phase diagrams were obtained by referring to the method in our previous work [45]. A certain amount of ChAAILs (or DESs) were added into a tube. Then, salt solution was added dropwise into the tube. The mixture became turbid after the addition of the salt. The mass fraction of all of the components was calculated at this turbidity point. The turbidity can disappear after further addition of some water. The mass fractions of all of the components were calculated, including ChAAILs (or DESs), salt, and water. Sufficient data for constructing the phase diagrams can be obtained by repeating the procedures above.

\subsection{Chiral Extraction of Phenylalanine Enantiomers in ATPS}

To a tube, a given amount of ChAAILs (or DESs), salt, the chiral selector HP- $\beta-C D$, and racemic phenylalanine were added. The solution was well mixed and was then centrifugated for quick and complete phase-forming. Two clear phases were observed after phase-forming, and the phase volume was noted down.

The enantiomers concentration in the bottom phase was quantified by HPLC. The enantiomers concentration in the top phase was also quantified to confirm whether the enantiomers precipitated on the middle phase interface or the tube bottom. The results proved that the enantiomers did not precipitate and were well dispersed in the ATPS; therefore, the corresponding enantiomers concentration in the top phase (IL-rich phase or DES-rich phase) can be obtained by subtraction. The distribution coefficients $(D)$ for $(S)$-Phe and (R)-Phe enantiomers were defined by Equations (1) and (2), respectively. The separation factor $(\alpha)$ for phenylalanine enantiomers was defined by Equation (3).

$$
\begin{gathered}
D_{\mathrm{S}}=C_{\mathrm{S} \text { top }} / C_{\mathrm{S} \text { bottom }} \\
D_{\mathrm{R}}=C_{\mathrm{R} \text { top }} / C_{\mathrm{R} \text { bottom }} \\
\alpha=D_{\mathrm{S}} / D_{\mathrm{R}}
\end{gathered}
$$

where $C_{\mathrm{S}}$ top and $C_{\mathrm{S} \text { bottom }}$ were the (S)-Phe concentration in the top and bottom phase, respectively. $C_{\mathrm{R} \text { top }}$ and $C_{\mathrm{R} \text { bottom }}$ were the $(R)$-Phe concentration in the top and bottom phase, respectively. The standard curves for the analysis of $(R)$-Phe and $(S)$-Phe enantiomers were $Y=0.0738 X-0.763$ $\left(R^{2}=0.9996\right)$ and $Y=0.0618 X-0.744\left(R^{2}=0.9996\right)$, respectively. Where $Y$ represents the peak area, $X$ represents the $(R)$-Phe or $(S)$-Phe enantiomer concentration. Standard solutions of phenylalanine enantiomers were in the range of $0.075-0.25 \mathrm{mg} / \mathrm{mL}$.

\subsection{Derivatization of Phenylalanine}

The copper complex was usually added to the mobile phase for the chiral separation of various enantiomers. The phenylalanine can form a complex with $\mathrm{Cu}^{2+}$ which can interfere with the analysis of phenylalanine $[46,47]$. The precolumn derivatization methods were used for the analysis of 
amino acid enantiomers by reversed phase HPLC [48]. Thus, the pretreatment of phenylalanine was done by derivatization reagents according to the reported methods with moderate modification [48]. The derivatization reagents were prepared by mixing $20 \mathrm{mg} O$-phthalaldehyde (OPA) and $20 \mathrm{mg}$ $\mathrm{N}$-acetyl-L-cysteine (NAC) into $2.0 \mathrm{~mL}$ ethanol, which was then diluted to $10 \mathrm{~mL}$ using sodium borate buffer $(\mathrm{pH}=9.8)$. The derivatization reagents were placed at $4{ }^{\circ} \mathrm{C}$ for further use. The derivatization of phenylalanine was done by mixing the phenylalanine samples and derivatization reagents at equal volume for $3 \mathrm{~min}$ before HPLC analysis.

\subsection{HPLC Conditions}

A Dionex UltiMate 3000 HPLC system (Dionex, Sunnyvale, CA, USA) coupled with a Kromasil C 18 chromatographic column $(250 \times 4.6 \mathrm{~mm}$ i.d., $5 \mu \mathrm{m})$ was used to analyze the phenylalanine enantiomers. The mobile phase was acetonitrile and sodium dihydrogen phosphate aqueous solution $(20 \mathrm{mmol} / \mathrm{L}$, $\mathrm{pH}=6.8$ ) at a volume ratio of 18:82. The flow rate: $0.8 \mathrm{~mL} / \mathrm{min}$ with isocratic elution; the detection wavelength: $350 \mathrm{~nm}$; the oven temperature: $30^{\circ} \mathrm{C}$; and the sample injection volume: $20 \mu \mathrm{L}$.

\section{Results and Discussion}

\subsection{Screening the Optimal ATPS Used for the Chiral Separation}

Phase diagrams can reflect the phase-forming ability and the components concentration that were needed for the construction of ATPS. A series of environmentally friendly ChAAILs and DESs were chosen as the potential components to form ATPS in this study. The phase diagrams of ATPSs composed of ChAAILs (or DESs) and potassium phosphate are shown in Figure 1. It can be seen that the phase-forming ability of ChAAILs with different amino acid anions followed the order of Pro $>$ Cys $>$ Ala $>$ His $>$ Phe $>$ Met $>$ Val (Figure 1a); that of DESs with different HBAs and HBDs followed this order: ChCl-LA $>$ ChCl-Sor $>$ ChCl-Urea $>$ Betaine-Glu $>$ Betaine-Gly $>$ Betaine-Urea (Figure 1b). It was reported in our previous work that the salting-out effect that the creation of water-ion complexes produces was the main driving force of the formation of ChAAILs (or DESs) ATPS [49]. The order of the phase-forming ability above is deriving from the difference of the hydrogen-bond electron pair donation ability of ChAAILs anions (or the HBDs), leading to the corresponding ability to form coordinative bonds and produce hydration complexes.

(a)

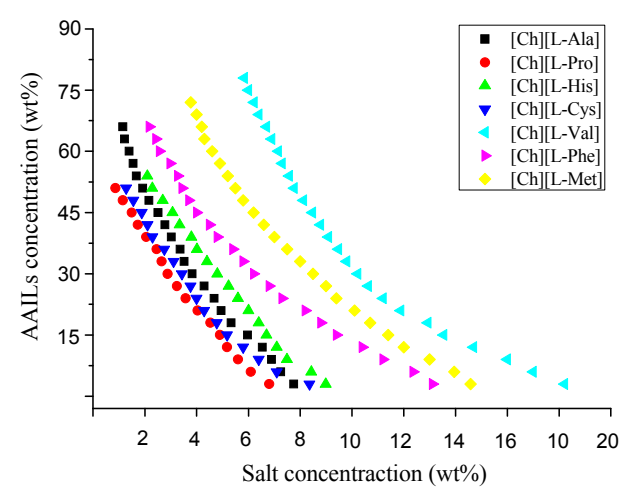

(b)

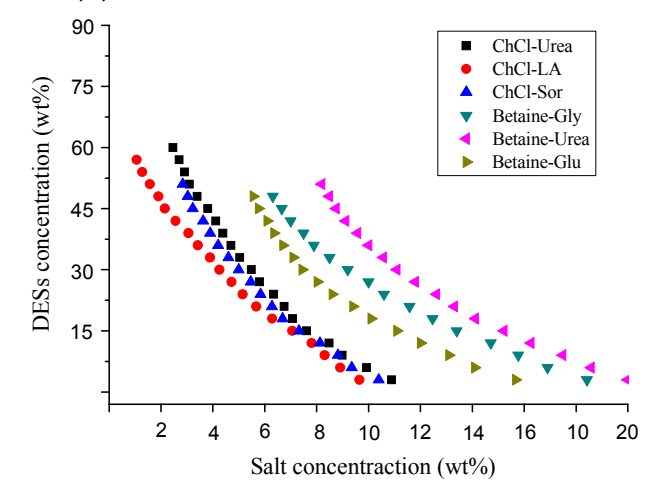

Figure 1. The phase diagrams for different ATPSs (aqueous two-phase systems): (a) ChAAILs (choline-amino acid ionic liquids) $/ \mathrm{K}_{3} \mathrm{PO}_{4}$ and (b) DESs (deep eutectic solvents) $/ \mathrm{K}_{3} \mathrm{PO}_{4}$ at $\mathrm{T}=298.15 \mathrm{~K}$.

The values of separation factor $(\alpha)$ for phenylalanine enantiomers using different ATPSs are shown in Figure 2. The results indicated that partial ChAAILs/salt systems generally had significantly higher resolution ability than the DESs/salt systems, which was interpreted as follows: the hydrogen-bond interaction between the HBAs and HBDs was partially destroyed by water in the ATPS, making the DESs/salt systems less suitable for the chiral extraction. The [Ch][L-Pro] $/ \mathrm{K}_{3} \mathrm{PO}_{4}$ system had the 
highest separation factor, which can maybe be attributed to the stronger interaction occurring between the anions of [Ch][L-Pro] and (S)-Phe, resulting in more (S)-Phe being extracted into the top phase. Thus, this [Ch][L-Pro] $/ \mathrm{K}_{3} \mathrm{PO}_{4}$ system was chosen for the further studies.

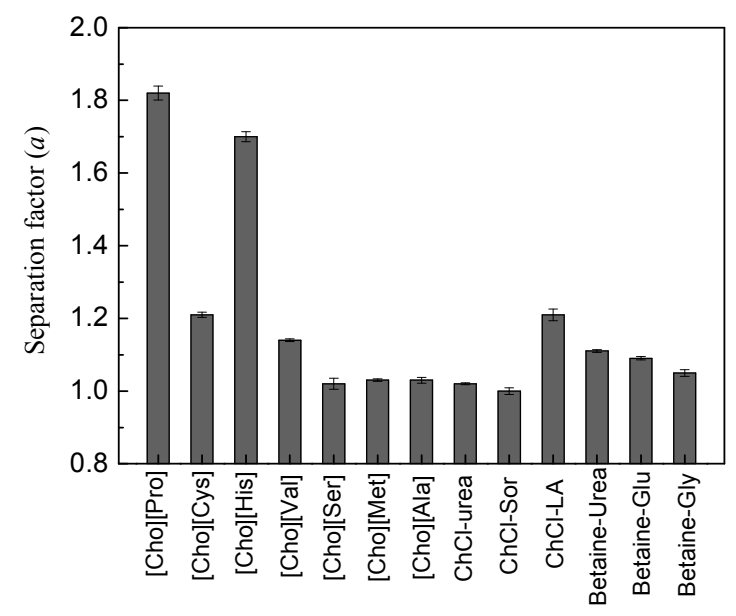

Figure 2. The separation factor $(\alpha)$ for different ATPSs composed of ChAAILs (or DESs) and $\mathrm{K}_{3} \mathrm{PO}_{4}$. The extraction conditions were as follow: $50 \mathrm{wt} \%$ ChAAILs (or DESs), $15 \mathrm{wt} \% \mathrm{~K}_{3} \mathrm{PO}_{4}, 30 \mathrm{mmol} / \mathrm{L}$ $\mathrm{HP}-\beta-\mathrm{CD}, 15 \mathrm{mg} / \mathrm{mL}$ phenylalanine. The experiments were performed at room temperature and without adjusting the system $\mathrm{pH}$.

\subsection{Effect of ChAAILs Concentration}

The ChAAILs concentration in the range from 25 to $60 \mathrm{wt} \%$ was investigated. When the ChAAILs concentration was $\leq 20 \mathrm{wt} \%$, no phase-separation was observed. Nevertheless, when the ChAAILs concentration reached $70 \mathrm{wt} \%$, the viscosity of ATPS was much higher, which was also not beneficial for the chiral extraction. The results in Figure 3 show that the highest $D$ and $\alpha$ values were obtained at the ChAAILs concentration of $30 \mathrm{wt} \%$. This can be interpreted as follows: the enantioselectivity increases with the increasing of ChAAILs concentration, while the ChAAILs concentration reaches a critical value, and the stability of the complex formed by chiral selector and enantiomers decreases leading to the decrease of the separation factor. Therefore, $30 \mathrm{wt} \%$ ChAAILs concentration was chosen for the further studies.

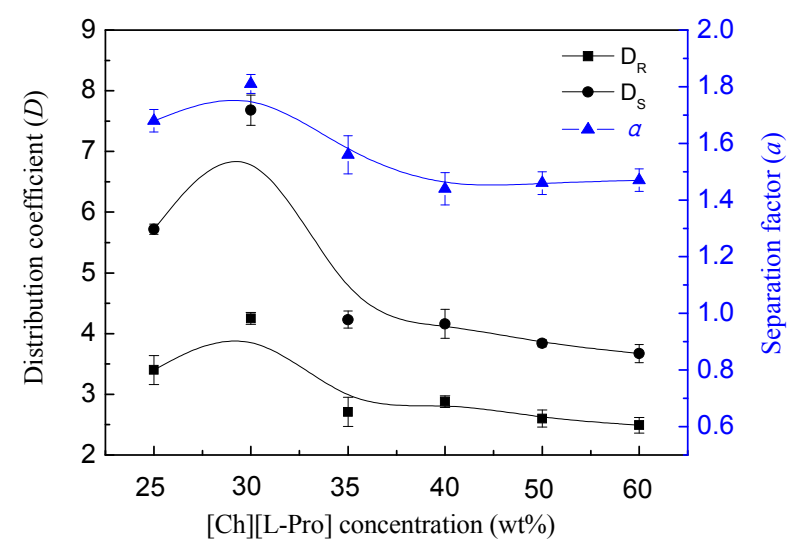

Figure 3. Effect of [Ch][L-Pro] concentration to the chiral extraction of phenylalanine enantiomers. The extraction conditions: $15.6 \mathrm{wt} \% \mathrm{~K}_{3} \mathrm{PO}_{4}, 40 \mathrm{mmol} / \mathrm{L} \mathrm{HP}-\beta-\mathrm{CD}, 15 \mathrm{mg} / \mathrm{mL}$ phenylalanine. The extraction experiments were performed at room temperature and without adjusting the system $\mathrm{pH}$. 


\subsection{Effect of Salt Type and Concentration}

Eleven types of salt were considered, including $\mathrm{K}_{2} \mathrm{CO}_{3}, \mathrm{Na}_{2} \mathrm{HPO}_{4}, \mathrm{Na}_{2} \mathrm{SO}_{4}, \mathrm{Na}_{3} \mathrm{C}_{6} \mathrm{H}_{5} \mathrm{O}_{7}$, $\mathrm{Na}_{2} \mathrm{CO}_{3}, \mathrm{~K}_{2} \mathrm{HPO}_{4}, \mathrm{KH}_{2} \mathrm{PO}_{4},\left(\mathrm{NH}_{4}\right)_{2} \mathrm{SO}_{4},\left(\mathrm{NH}_{4}\right)_{3} \mathrm{PO}_{4}, \mathrm{~K}_{3} \mathrm{PO}_{4}$, and $\mathrm{KNO}_{3}$. It was found that the phenylalanine that was precipitated in the systems formed by acidic salt or neutral salt. Moreover, only the basic salt potassium phosphate and dipotassium phosphate can form the ATPS with [Ch][L-Pro]. The [Ch][L-Pro] $/ \mathrm{K}_{3} \mathrm{PO}_{4}$ system $(\alpha=1.82)$ had higher chiral resolution ability than the [Ch][L-Pro] $/ \mathrm{K}_{2} \mathrm{HPO}_{4}$ system $(\alpha=1.42)$ under similar conditions, thus this system was chosen for further studies.

To optimize the $\mathrm{K}_{3} \mathrm{PO}_{4}$ concentration, the salt concentration of $7.8-15.6 \mathrm{wt} \%$ was investigated. When the salt concentration was lower than $7.8 \mathrm{wt} \%$, the ATPS could not be formed; while it was higher than $15.6 \mathrm{wt} \%$, the HP- $\beta$-CD precipitated. The results in Figure 4 show that both the $D$ and $\alpha$ values decreased with the increasing of salt concentration, and the highest $D$ and $\alpha$ values were obtained at $7.8 \mathrm{wt} \% \mathrm{~K}_{3} \mathrm{PO}_{4}$ concentration. This can be interpreted as a fact that the increase of salt in ATPS can make more free water enter into the bottom phase [50]. The decrease of water in the top phase can cause the unobvious stability difference between (R)-Phe and (S)-Phe [30], making this ATPS unsuitable for the chiral extraction.

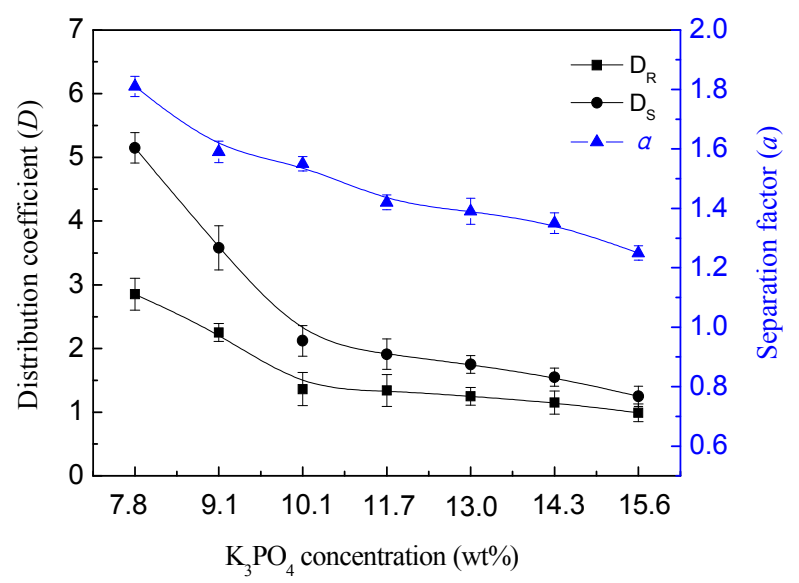

Figure 4. Effect of $\mathrm{K}_{3} \mathrm{PO}_{4}$ concentration to the chiral extraction of phenylalanine enantiomers. The extraction conditions were as follow: $30 \mathrm{wt} \%$ [Ch][L-Pro], $40 \mathrm{mmol} / \mathrm{L} \mathrm{HP}-\beta-\mathrm{CD}, 15 \mathrm{mg} / \mathrm{mL}$ phenylalanine. The extraction experiments were done at room temperature and without adjusting the system $\mathrm{pH}$.

\subsection{Effect of HP- $\beta-C D$ Concentration}

HP- $\beta-C D$ has good solubility in water, which was widely selected as the chiral selector in enantioselective extraction of various chiral compounds [26,51,52]. The HP- $\beta-C D$ affecting the chiral recognition action can be attributed to some special structures and features of complexes formed by HP- $\beta-C D$ and phenylalanine enantiomers, such as the inclusion interaction, electrostatic interaction, and hydrogen bond interaction [53]. The insufficient chiral selectors lead to inefficient chiral extraction, while excess chiral selectors result in waste and are even adverse to the enantioselective extraction. Thus, the HP- $\beta-C D$ concentration in the range from 10 to $50 \mathrm{mmol} / \mathrm{L}$ was studied. Simultaneously, one more sample was prepared with the same components, however without the addition of HP- $\beta-C D$, and was used as the control. The result showed that no enantiomeric separation effect was observed. The results in Figure 5 show that the maximum $D$ and $\alpha$ values were obtained at $40 \mathrm{mmol} / \mathrm{L} \mathrm{HP}-\beta-\mathrm{CD}$. The excess chiral selectors may hinder the formation of complexes, which resulted in the decrease of the recognition ability [54]. Therefore, $40 \mathrm{mmol} / \mathrm{L} \mathrm{HP}-\beta-C D$ was chosen for further studies. 


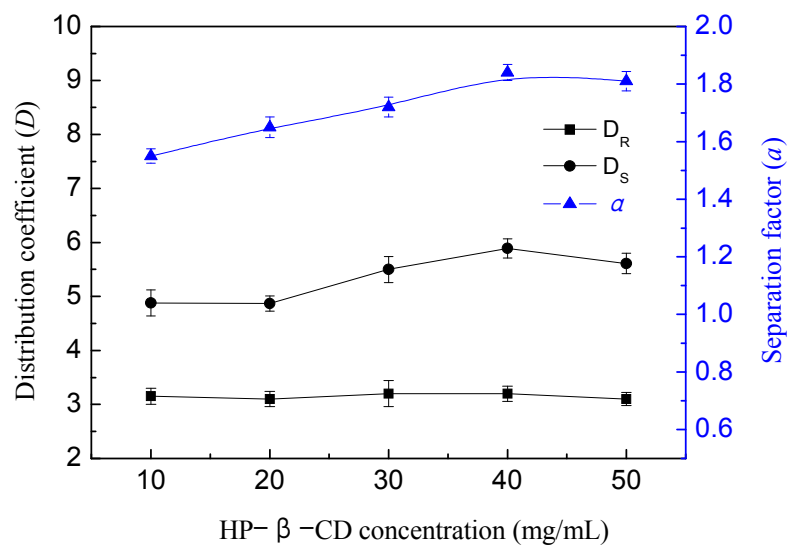

Figure 5. Effect of HP- $\beta-C D$ concentration on the chiral extraction of phenylalanine enantiomers. The extraction conditions were as follows: $30 \mathrm{wt} \%$ [Ch][L-Pro], $7.8 \mathrm{wt} \% \mathrm{~K}_{3} \mathrm{PO}_{4}, 15 \mathrm{mg} / \mathrm{mL}$ phenylalanine. The extraction experiments were done at room temperature and without adjusting the system $\mathrm{pH}$.

\subsection{Effect of Phenylalanine Concentration}

The effect of phenylalanine concentration was studied in the range of $2.5-20 \mathrm{mg} / \mathrm{mL}$. As it is shown in Figure 6, the $D_{\mathrm{R}}$ values varied little and the $D_{\mathrm{S}}$ values increased with the increasing of phenylalanine concentration, which indicates that the (S)-Phe was more sensitive to this chiral extraction system. The maximum $D$ and $\alpha$ values were obtained at the phenylalanine concentration of $15 \mathrm{mg} / \mathrm{mL}$, thus, this concentration was chosen for further studies.

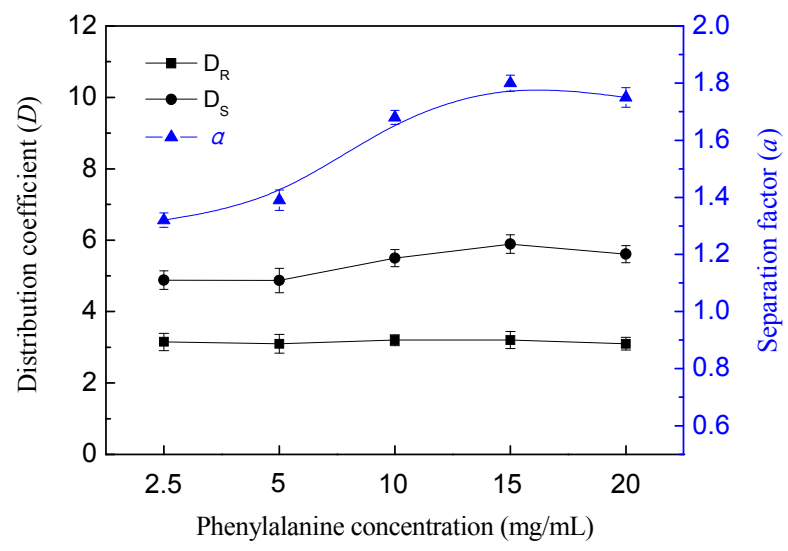

Figure 6. Effect of phenylalanine concentration on the chiral extraction of phenylalanine enantiomers. The extraction conditions were as follows: $30 \mathrm{wt} \%$ [Ch][L-Pro], 7.8wt $\% \mathrm{~K}_{3} \mathrm{PO}_{4}, 40 \mathrm{mmol} / \mathrm{L} \mathrm{HP}-\beta-\mathrm{CD}$. The extraction experiments were done at room temperature and without adjusting the system $\mathrm{pH}$.

\subsection{Effect of System $\mathrm{pH}$}

The optimum [Ch][L-Pro] $/ \mathrm{K}_{3} \mathrm{PO}_{4}$ ATPS led to a system $\mathrm{pH}$ around 14.0. The $\mathrm{pH}$ of 8.0-14.0 was adjusted using phosphoric acid solution. The phase-separation cannot be achieved below $\mathrm{pH}$ 8.0 because the lower $\mathrm{pH}$ destroys the ionization balance of $\left[\mathrm{PO}_{4}{ }^{3-}\right]$ in aqueous solution. The results shown in Figure 7 indicate that the $D$ and $\alpha$ values generally decreased with the increasing of system $\mathrm{pH}$, and the maximum $\alpha$ value was obtained at $\mathrm{pH}$ 8.0. The phenylalanine readily dissolved in the basic solution in the form of phenylalanine anion, and when the system $\mathrm{pH}$ was below 8.0, the solubility of phenylalanine decreased and then the phenylalanine precipitated. Therefore, the system $\mathrm{pH} 8.0$ was chosen in this study. 


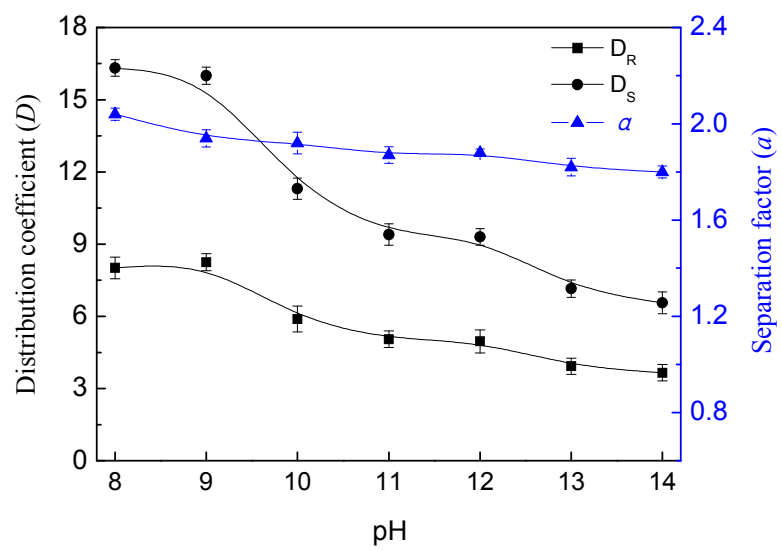

Figure 7. Effect of system $\mathrm{pH}$ on the chiral extraction of phenylalanine enantiomers. The extraction conditions were as follows: $30 \mathrm{wt} \%$ [Ch][L-Pro], $7.8 \mathrm{wt} \% \mathrm{~K}_{3} \mathrm{PO}_{4}, 40 \mathrm{mmol} / \mathrm{L} \mathrm{HP}-\beta-\mathrm{CD}, 15 \mathrm{mg} / \mathrm{mL}$ phenylalanine. The extraction experiments were done at room temperature.

\subsection{Effect of Operation Temperature}

The effect of temperature in the range from 4 to $60^{\circ} \mathrm{C}$ was studied. The results in Figure 8 indicate that the maximum $D$ value was obtained at $20^{\circ} \mathrm{C}$, which indicates that more phenylalanine was extracted into the top phase with the increasing of temperature. However, the further increasing of temperature was not suitable for this chiral extraction. The $\alpha$ values decreased with the increasing of temperature, and the maximum $\alpha$ of 2.05 was obtained at $4{ }^{\circ} \mathrm{C}$. This can be interpreted as a fact that the complexation of phenylalanine enantiomers and HP- $\beta-C D$ is an enthalpically driven process [53], and the complexes formed by (R)-Phe or (S)-Phe with HP- $\beta$-CD are both not stable at higher temperature, meanwhile the recognition difference between the two enantiomers becomes smaller at higher temperatures. The results obtained are in agreement with the previous work about the chiral separation of other racemic mixture [55]. Thus, the chiral extraction can be operated at $4{ }^{\circ} \mathrm{C}$.

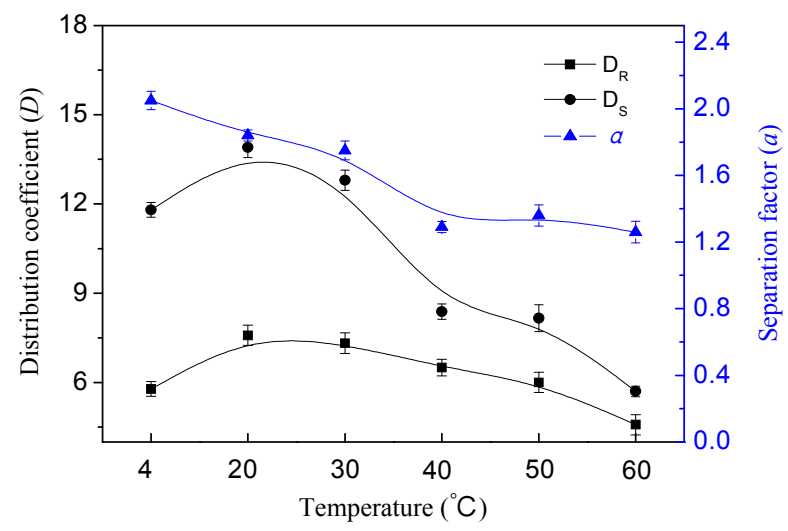

Figure 8. Effect of temperature on the chiral extraction of phenylalanine enantiomers. The extraction conditions were as follows: $30 \mathrm{wt} \%$ [Ch][L-Pro], $7.8 \mathrm{wt} \% \mathrm{~K}_{3} \mathrm{PO}_{4}, 40 \mathrm{mmol} / \mathrm{L} \mathrm{HP}-\beta-\mathrm{CD}, 15 \mathrm{mg} / \mathrm{mL}$ phenylalanine, and system $\mathrm{pH}$ 8.0.

Under the optimized conditions, this method can obtain better or almost close enantiomeric separation effect compared with the chiral separation of phenylalanine enantiomers using PEG/salt [26] and IL/salt [29] ATPSs. The chromatograms for the standard phenylalanine, the phenylalanine sample in the top and bottom phase are shown in Figure 9. The results proved that the phenylalanine was mainly extracted into the top phase. Those results can be attributed to the reason that the much stronger coordinated action occurred between phenylalanine anion and [Ch][L-Pro] at the basic condition, resulting in the majority of phenylalanine enantiomers being extracted in the 
top phase [30]. Moreover, the peak area of (S)-Phe was larger than that of $(R)$-Phe in the top phase, whilst the former was smaller than the latter in the bottom phase, which proved that $(S)$-Phe was more easily extracted into the top phase than $(R)$-Phe. Thus, the (S)-Phe was preferentially recognized by this ATPS in the top phase.

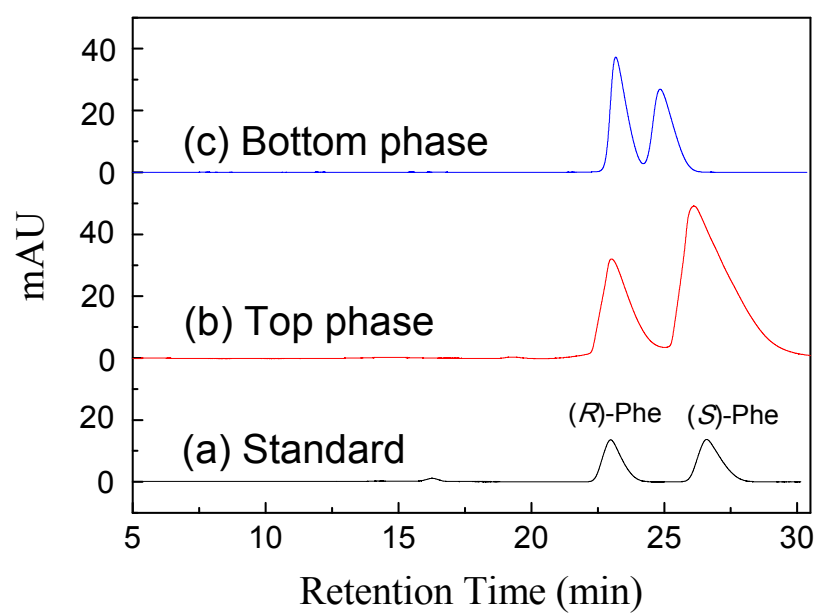

Figure 9. The HPLC chromatograms for phenylalanine enantiomers in ATPS. (a) phenylalanine standard, (b) phenylalanine sample withdrawn in the top phase, and (c) phenylalanine sample withdrawn in the bottom phase.

\section{Conclusions}

In this study, some environmentally friendly ATPSs based on ChAAILs (or DESs) and salt were developed for the chiral extraction of phenylalanine enantiomers. The [Ch][L-Pro] $/ \mathrm{K}_{3} \mathrm{PO}_{4}$ system was screened as the optimum system. Under the following conditions: $30 \mathrm{wt} \%$ [Ch][L-Pro], $7.8 \mathrm{wt} \% \mathrm{~K}_{3} \mathrm{PO}_{4}$, $40 \mathrm{mmol} / \mathrm{L} \mathrm{HP}-\beta-\mathrm{CD}, 15 \mathrm{mg} / \mathrm{mL}$ phenylalanine, $4{ }^{\circ} \mathrm{C}$ operation temperature, and system $\mathrm{pH} 8.0$, the maximum $\alpha$ value of 2.05 was obtained. The phenylalanine enantiomers were mainly extracted into the top phase (ChAAILs-rich phase), and the (S)-Phe was preferentially recognized by the chiral selector in the top phase. This ATPS being used for the enantioselective extraction of phenylalanine enantiomers is considerably more green, simple, and rapid compared to conventional enantioselective liquid-liquid extraction, and has the potential to be used in the chiral extraction of other enantiomers.

Author Contributions: Z.T. and F.L. conceived and designed the experiments. D.S., R.W. and L.L. performed the experiments. Z.T. and D.S analyzed the data. Z.T. wrote and revised the paper. R.W. revised the paper.

Funding: This research was funded by the National Natural Science Foundation of China (21878326 and 21406262), the Agricultural Science and Technology Innovation Program (ASTIP-IBFC07), and the Changsha City Outstanding innovative Youth Project.

Conflicts of Interest: The authors declare no conflict of interest.

\section{References}

1. Guo, J.H.; Wu, J.Y.; Siuzdak, G.; Finn, M.G. Measurement of enantiomeric excess by kinetic resolution and mass spectrometry. Angew. Chem. Int. Ed. 1999, 38, 1755-1758. [CrossRef]

2. Martens, J.; Gunther, K.; Schickedanz, M. Resolution of optical isomers by thin-layer chromatography: Enantiomeric purity of methyldopa. Arch. Pharm. 1986, 319, 572-574. [CrossRef]

3. Bezhitashvili, L.; Bardavelidze, A.; Ordjonikidze, T.; Chankvetadze, L.; Chity, M.; Farkas, T.; Chankvetadze, B. Effect of pore-size optimization on the performance of polysaccharide-based superficially porous chiral stationary phases for the separation of enantiomers in high-performance liquid chromatography. J. Chromatogr. A 2017, 1482, 32-38. [CrossRef] [PubMed]

4. Xie, S.-M.; Yuan, L.-M. Recent progress of chiral stationary phases for separation of enantiomers in gas chromatography. J. Sep. Sci. 2017, 40, 124-137. [CrossRef] [PubMed] 
5. Ali, I.; Sanagi, M.M.; Aboul-Enein, H.Y. Advances in chiral separations by nonaqueous capillary electrophoresis in pharmaceutical and biomedical analysis. Electrophoresis 2014, 35, 926-936. [CrossRef] [PubMed]

6. Lee, J.; Oh, Y.; Choi, Y.K.; Choi, E.; Kim, K.; Park, J.; Kim, M.J. Dynamic kinetic resolution of diarylmethanols with an activated lipoprotein lipase. Acs Catal. 2014, 5, 683-689. [CrossRef]

7. Ren, L.; Zhu, S.; Shi, Y.; Gao, S.; Zheng, G. Enantioselective resolution of gamma-lactam by a novel thermostable type ii (+)-gamma-lactamase from the hyperthermophilic archaeon aeropyrum pernix. Appl. Biochem. Biotechnol. 2015, 176, 170-184. [CrossRef] [PubMed]

8. Sueyoshi, Y.; Fukushima, C.; Yoshikawa, M. Molecularly imprinted nanofiber membranes from cellulose acetate aimed for chiral separation. J. Membr. Sci. 2010, 357, 90-97. [CrossRef]

9. Tang, K.; Zhang, H.; Zhang, P. Continuous separation of $\alpha$-cyclohexyl-mandelic acid enantiomers by enantioselective liquid-liquid extraction in centrifugal contactor separators: Experiments and modeling. Ind. Eng. Chem. Res. 2013, 52, 3893-3902. [CrossRef]

10. Huang, X.; Wu, H.; Wang, Z.; Luo, Y.; Song, H. High resolution of racemic phenylalanine with dication imidazolium-based chiral ionic liquids in a solid-liquid two-phase system. J. Chromatogr. A 2017, 1479, $48-54$. [CrossRef] [PubMed]

11. Wu, J.; Su, P.; Huang, J.; Wang, S.; Yang, Y. Synthesis of teicoplanin-modified hybrid magnetic mesoporous silica nanoparticles and their application in chiral separation of racemic compounds. J. Colloid Interface Sci. 2013, 399, 107-114. [CrossRef] [PubMed]

12. Huang, X.; Wang, J.; Wang, Q.; Huang, B. Chiral speciation and determination of dl-selenomethionine enantiomers on a novel chiral ligand-exchange stationary phase. Anal. Sci. 2005, 21, 253-257. [CrossRef] [PubMed]

13. Navarro-Sanchez, J.; Argente-Garcia, A.I.; Moliner-Martinez, Y.; Roca-Sanjuan, D.; Antypov, D.; Campins-Falco, P.; Rosseinsky, M.J.; Marti-Gastaldo, C. Peptide metal-organic frameworks for enantioselective separation of chiral drugs. J. Am. Chem. Soc. 2017, 139, 4294-4297. [CrossRef] [PubMed]

14. Tang, K.; Feng, X.; Zhang, P.; Xu, W. Experimental and model study on separation of $\alpha$-cyclopentylmandelic acid enantiomers by liquid-liquid extraction. J. Chem. Eng. Data 2016, 61, 3090-3097. [CrossRef]

15. Tan, Z.; Li, F.; Zhao, C.; Teng, Y.; Liu, Y. Chiral separation of mandelic acid enantiomers using an aqueous two-phase system based on a thermo-sensitive polymer and dextran. Sep. Purif. Technol. 2017, 172, 382-387. [CrossRef]

16. Albertsson, P.A. Partition of Cell Particles and Macromolecules; Wiley: New York, NY, USA, 1986.

17. Liu, C.L.; Nikas, Y.J.; Blankschtein, D. Novel bioseparations using two-phase aqueous micellar systems. Biotechnol. Bioeng. 1996, 52, 185-192. [CrossRef]

18. Bertrand, B.; Mayolo-Deloisa, K.; Gonzalez-Gonzalez, M.; Tinoco-Valencia, R.; Serrano-Carreon, L.; Martinez-Morales, F.; Trejo-Hernandez, M.R.; Rito-Palomares, M. Pleurotus ostreatus laccase recovery from residual compost using aqueous two-phase systems. J. Chem. Technol. Biotechnol. 2016, 91, 2235-2242. [CrossRef]

19. Liu, J.; Cao, X. Preparation of novel alkaline ph-responsive copolymers for the formation of recyclable aqueous two-phase systems and their application in the extraction of lincomycin. J. Sep. Sci. 2016, 39, 584-594. [CrossRef] [PubMed]

20. Ooi, C.W.; Tey, B.T.; Hii, S.L.; Mazlina, S.; Kamal, M.; Lan, J.C.W.; Ariff, A.; Ling, T.C. Purification of lipase derived from burkholderia pseudomallei with alcohol/salt-based aqueous two-phase systems. Process Biochem. 2009, 44, 1083-1087. [CrossRef]

21. Gutowski, K.E.; Broker, G.A.; Willauer, H.D.; Huddleston, J.G.; Swatloski, R.P.; Holbrey, J.D.; Rogers, R.D. Controlling the aqueous miscibility of ionic liquids: Aqueous biphasic systems of water-miscible ionic liquids and water-structuring salts for recycle, metathesis, and separations. J. Am. Chem. Soc. 2003, 125, 6632-6633. [CrossRef] [PubMed]

22. Farias, F.O.; Passos, H.; Sanglard, M.G.; Igarashi-Mafra, L.; Coutinho, J.A.P.; Mafra, M.R. Designer solvent ability of alcohols in aqueous biphasic systems composed of deep eutectic solvents and potassium phosphate. Sep. Purif. Technol. 2018, 200, 84-93. [CrossRef]

23. Grilo, A.L.; Raquel Aires-Barros, M.; Azevedo, A.M. Partitioning in aqueous two-phase systems: Fundamentals, applications and trends. Sep. Purif. Rev. 2016, 45, 68-80. [CrossRef] 
24. Tan, L.; Long, Y.; Jiao, F.; Chen, X. Enantioselective extraction of mandelic acid enantiomers by aqueous two-phase systems of polyethylene glycol and ammonium sulfate containing $\beta$-cyclodextrin as chiral selector. J. Iran Chem. Soc. 2011, 8, 889-896. [CrossRef]

25. Ni, Y.; Zhou, J.; Sun, Z. Production of a key chiral intermediate of betahistine with a newly isolated kluyveromyces sp. In an aqueous two-phase system. Process Biochem. 2012, 47, 1042-1048. [CrossRef]

26. Chen, X.; Liu, L.; Jiao, F.; Wang, Z. Extraction of phenylalanine enantiomers by aqueous two phase systems containing combinatorial chiral selector. Chin. J. Chem. 2012, 30, 965-969. [CrossRef]

27. Chen, X.-Q.; Dong, Q.-L.; Yu, J.-G.; Jiao, F.-P. Extraction of tryptophan enantiomers by aqueous two-phase systems of ethanol and (nh4)2so4. J. Chem. Technol. Biotechnol. 2013, 88, 1545-1550. [CrossRef]

28. Chen, Z.; Zhang, W.; Wang, L.; Fan, H.; Wan, Q.; Wu, X.; Tang, X.; Tang, J.Z. Enantioseparation of racemic flurbiprofen by aqueous two-phase extraction with binary chiral selectors of 1-dioctyl tartrate and L-tryptophan. Chirality 2015, 27, 650-657. [CrossRef] [PubMed]

29. Wu, D.; Zhou, Y.; Cai, P.; Shen, S.; Pan, Y. Specific cooperative effect for the enantiomeric separation of amino acids using aqueous two-phase systems with task-specific ionic liquids. J. Chromatogr. A 2015, 1395, 65-72. [CrossRef] [PubMed]

30. Wu, H.; Yao, S.; Qian, G.; Yao, T.; Song, H. A resolution approach of racemic phenylalanine with aqueous two-phase systems of chiral tropine ionic liquids. J. Chromatogr. A 2015, 1418, 150-157. [CrossRef] [PubMed]

31. Docherty, K.M.; Kulpa, J.C.F. Toxicity and antimicrobial activity of imidazolium and pyridinium ionic liquids. Green Chem. 2005, 7, 185-189. [CrossRef]

32. Thuy Pham, T.P.; Cho, C.-W.; Yun, Y.-S. Environmental fate and toxicity of ionic liquids: A review. Water Res. 2010, 44, 352-372. [CrossRef] [PubMed]

33. Wu, S.; Zeng, L.; Wang, C.; Yang, Y.; Zhou, W.; Li, F.; Tan, Z. Assessment of the cytotoxicity of ionic liquids on spodoptera frugiperda 9 (sf-9) cell lines via in vitro assays. J. Hazard. Mater. 2018, 348, 1-9. [CrossRef] [PubMed]

34. Hou, X.-D.; Smith, T.J.; Li, N.; Zong, M.-H. Novel renewable ionic liquids as highly effective solvents for pretreatment of rice straw biomass by selective removal of lignin. Biotechnol. Bioeng. 2012, 109, 2484-2493. [CrossRef] [PubMed]

35. Radosevic, K.; Zeleznjak, J.; Cvjetko Bubalo, M.; Radojcic Redovnikovic, I.; Slivac, I.; Gaurina Srcek, V. Comparative in vitro study of cholinium-based ionic liquids and deep eutectic solvents toward fish cell line. Ecotoxicol. Environ. Saf. 2016, 131, 30-36. [CrossRef] [PubMed]

36. Smith, E.L.; Abbott, A.P.; Ryder, K.S. Deep eutectic solvents (dess) and their applications. Chem. Rev. 2014, 114, 11060-11082. [CrossRef] [PubMed]

37. Zhang, Q.; De Oliveira Vigier, K.; Royer, S.; Jerome, F. Deep eutectic solvents: Syntheses, properties and applications. Chem. Soc. Rev. 2012, 41, 7108-7146. [CrossRef] [PubMed]

38. Tang, B.; Zhang, H.; Row, K.H. Application of deep eutectic solvents in the extraction and separation of target compounds from various samples. J. Sep. Sci. 2015, 38, 1053-1064. [CrossRef] [PubMed]

39. Zhao, B.-Y.; Xu, P.; Yang, F.-X.; Wu, H.; Zong, M.-H.; Lou, W.-Y. Biocompatible deep eutectic solvents based on choline chloride: Characterization and application to the extraction of rutin from sophora japonica. ACS Sustain. Chem. Eng. 2015, 3, 2746-2755. [CrossRef]

40. Fu, N.; Lv, R.; Guo, Z.; Guo, Y.; You, X.; Tang, B.; Han, D.; Yan, H.; Row, K.H. Environmentally friendly and non-polluting solvent pretreatment of palm samples for polyphenol analysis using choline chloride deep eutectic solvents. J. Chromatogr. A 2017, 1492, 1-11. [CrossRef] [PubMed]

41. Gouveia, W.; Jorge, T.F.; Martins, S.; Meireles, M.; Carolino, M.; Cruz, C.; Almeida, T.V.; Araujo, M.E.M. Toxicity of ionic liquids prepared from biomaterials. Chemosphere 2014, 104, 51-56. [CrossRef] [PubMed]

42. Wang, R.; Chang, Y.; Tan, Z.; Li, F. Applications of choline amino acid ionic liquid in extraction and separation of flavonoids and pectin from ponkan peels. Sep. Sci. Technol. 2016, 51, 1093-1102. [CrossRef]

43. De, S.S.; Masci, G.; Casciotta, F.; Caminiti, R.; Scarpellini, E.; Campetella, M.; Gontrani, L. Cholinium-amino acid based ionic liquids: A new method of synthesis and physico-chemical characterization. Phys. Chem. Chem. Phys. 2015, 17, 20687.

44. Duan, L.; Dou, L.-L.; Guo, L.; Li, P.; Liu, E.H. Comprehensive evaluation of deep eutectic solvents in extraction of bioactive natural products. ACS Sustain. Chem. Eng. 2016, 4, 2405-2411. [CrossRef] 
45. Tan, Z.; Li, F.; Xu, X. Isolation and purification of aloe anthraquinones based on an ionic liquid/salt aqueous two-phase system. Sep. Purif. Technol. 2012, 98, 150-157. [CrossRef]

46. Forsman, U. Enantiomeric resolution of an optically active guanine derivative by high-performance liquid chromatography with phenylalanine-cu(ii) in the mobile phase. J. Chromatogr. A 1984, 303, 217-221. [CrossRef]

47. Altun, O.; Bilcen, S. Spectroscopic characterization of $\mathrm{Cu}$ (ii) complex of L-phenylalanine and D,L-tryptophan. Spectrochim. Acta A 2010, 75, 789-793. [CrossRef] [PubMed]

48. Kelly, M.T.; Blaise, A.; Larroque, M. Rapid automated high performance liquid chromatography method for simultaneous determination of amino acids and biogenic amines in wine, fruit and honey. J. Chromatogr. A 2010, 1217, 7385-7392. [CrossRef] [PubMed]

49. Wang, R.; Chang, Y.; Tan, Z.; Li, F. Phase behavior of aqueous biphasic systems composed of novel choline amino acid ionic liquids and salts. J. Mol. Liq. 2016, 222, 836-844. [CrossRef]

50. Li, F.; Li, Q.; Wu, S.; Tan, Z. Salting-out extraction of allicin from garlic (Allium sativum L.) based on ethanol/ammonium sulfate in laboratory and pilot scale. Food Chem. 2017, 217, 91-97. [CrossRef] [PubMed]

51. Rong, L.; Liu, Q.; Wang, J.; Zeng, H.; Yang, H.; Chen, X. Enantioseparation of (rs)-ibuprofen by closed recycling high-speed counter-current chromatography using hydroxypropyl- $\beta$-cyclodextrin as chiral selector. Tetrahedron 2016, 27, 301-306. [CrossRef]

52. Zhang, P.; Sun, G.; Tang, K.; Yang, W.; Sui, G.; Zhou, C. Enantiomeric separation of oxybutynin by recycling high-speed counter-current chromatography with hydroxypropyl- $\beta$-cyclodextrin as chiral selector. J. Sep. Sci. 2014, 37, 3443-3450. [CrossRef] [PubMed]

53. Li, L.-H.; Li, F.-F. Chiral separation of alpha-cyclohexyl-mandelic-acid by aqueous two phase system combined with cu-2-beta-cyclodextrin complex. Chem. Eng. J. 2012, 211, 240-245. [CrossRef]

54. Li, F.-F.; Tan, Z.-J.; Guo, Z.-F. Enantioseparation of mandelic acid and alpha-cyclohexylmandelic acid using an alcohol/salt-based aqueous two-phase system. Chem. Pap. 2014, 68, 1539-1545. [CrossRef]

55. Wang, Z.; Hou, Z.; Yao, S.; Lin, M.; Song, H. A new and recyclable system based on tropin ionic liquids for resolution of several racemic amino acids. Anal. Chim. Acta 2017, 960, 81-89. [CrossRef] [PubMed] 